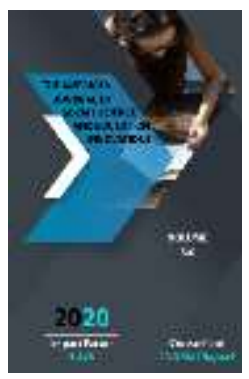

\title{
Artistic Depiction Of The Image Of Avaz In The Epics "Gorogly"
}

\author{
Jonmirza Nematovich Mirzaev \\ Director Of Information Resource Center Of The Tashkent State University Of Uzbek \\ Language And Literature Named After Alisher Navoi, Tashkent, Uzbekistan
}

Journal Website: http://usajournalshub.c om/index,php/tajssei

Copyright: Original content from this work may be used under the terms of the creative commons attributes 4.0 licence.

\section{ABSTRACT}

This article deals with the artistic image of the image of Avaz in the epics "Gorogly". The epic "Gorogly" is one of the most popular folk epics not only among the Uzbek and fraternal Turkic peoples, but also among the peoples of the East. There are different series of epics, among which are the epics associated with the image of Avaz. There is much in common between the Uzbek and Tajik versions of the epic Gorogly, and this similarity is manifested primarily in artistic images, in their artistic image.

In this article, which analyzes the Uzbek and Tajik versions of the epic "Gorogly", the issues of artistic representation of the image of Avaz are covered in detail, and we see that the means of artistic representation in the epic are based on the psyche, mythological imagination and aesthetic attitude to reality.

\section{KEYWORDS}

"Gorogly" series, version, variant, image, artistic interpretation, artistic image, mythological imagination.

\section{INTRODUCTION}

The ethnic and cultural closeness of the peoples of Azerbaijan, Asia Minor and Central Asia naturally influenced the folklore of peoples and ethnic groups that have lived side by side for a long time. In particular, it is natural that the peoples who have lived together for centuries in one kingdom, one civilization, one civilization, have a holistic 
aesthetic approach not only in terms of culture and statehood, but also in terms of artistic and creative relations. The closeness of aesthetic relations to reality has led to the folklorization of the historical events experienced in this country together, of course, each ethnos based on its own traditions. Therefore, although there is a view in science that the epic "Gorogly" appeared in Asia Minor and Azerbaijan in the XVI century as the historical basis and core [1], but in the formation of this epic, in its transformation into a perfect epic, all peoples and nations present today and contributed equally to the enrichment of his artistic and poetic. For this reason, the artistic value of the epic "Gorogly" can not be analyzed in isolation from one nation, one ethnos. In order to determine the poetic, mythological, historical, social essence, scale, place of the epic in the epic of the peoples of the world, it is necessary to study and analyze the artistic, poetic, aesthetic and historical life of all peoples. In this sense, the epic "Gorogly" is a common property and a common aesthetic and artistic heritage of the peoples of Asia Minor, Azerbaijan and Central Asia. However, at the same time, the process of formation and artistic rhythm of the epic is different in different peoples, depending on the epic traditions. Every national poet instills in the epic the dreams, legends and values of the peoples to which he belongs, based on this epic tradition. Although the core, plot, and fable look the same, the epic "Gorogly" of different rights is formed as an example of pure national artistic and aesthetic thinking, which is unique to different peoples. Artistic and aesthetic thinking reflects everything, history, ethnography, social life, culture, power of the people. Therefore, recognizing that the epic "Gorogly" of each nation is closely linked with the cultural, historical and artistic thinking of this nation, it is necessary to recognize that the interaction of oral creativity was a key attribute in the formation of this epic.

\section{MAIN PART}

As you know, an epic work is analyzed either from a historical-genetic or artistic-aesthetic point of view. It is the artistic and aesthetic aspect that provides folklore with great material. Thus, the epic is a product of the artistic creativity of the people, reflecting the original views of the people's consciousness. Therefore, in the artistic analysis of the epic, Gegel called the epic "folk bible", implying the discovery of the ideological and aesthetic, the universe, society, human essence of the work. [2. 231] I.S. Braginsky also argues that the analysis of the artistic and aesthetic layers of the epic provides sufficient information and imagination not only about the artisticaesthetic, but also about the attitudes of historical and social life of this people. [3. 7-8] The artistic depiction of the epic "Gorogly", in particular, the image of Avaz in both epics allows us to enter and analyze the artistic and aesthetic world of the two peoples. The people of Azerbaijan, Asia Minor and Central Asia are close to the image of Avaz in the epic "Gorogly", but their attitudes to it, the lines, the task assigned to it, the artistic description are radically different.

In particular, in the Azerbaijani and Anatolian versions, Avaz Gorogly is one of the forty young men abducted, which means that he is not assigned any task in an epic sense. In the Turkmen version, Avaz does not rise to the level of an epic alp. For Shunigng, too, Avaz's non-existent artistic expression is interpreted as one of his forty haircuts, and he is treated with these qualities.

In the Uzbek version, the image of Avaz is one of the main protagonists after Gorogly, the 
main successor of Gorgly, i.e. the epic alp, the heir alp, according to his artistic lines and character, the epic alp. Artistic images are also applied to it from this point of view. In the Uzbek version, it is embodied as an epic alp that combines both romantic and heroic features. These two features, of course, also affect artistic expression. therefore, the bakhshis derive the image from the vapzif entrusted to it, adopting traditional epic expressions, epithets, and the colors of love or heroism are also exaggerated accordingly. In the Tajik version, he fully embodies only the features of the hero of the heroic epic. Therefore, in the Tajik version, we find more heroic epic expressions in the image of Avaz. As I.S. Braginsky points out, unlike the Turkic peoples, the Tajik epic "Gorogly" focuses on Avaz, not Gorogly. In other words, in the Tajik version, the main protagonist of the epic is Avaz. The image of Gorogly becomes an almost episodic character after the first two epics of the epic. From the second epic, that is, when Avaz entered the epic, Gorogly is interpreted as an old sultan over ninety. For this reason, the alpine passes from Gorogly to Avaz. The heroism of Avaz, and then his son Nurali, comes to the fore in the epic, "Avaz is at the center of the events, the plot of the epic revolves around his heroism." [3. 31] In this sense, the image of Gorogly, according to the epic law, occupies a relatively secondary place. Therefore, the main hero of the Tajik epic Avaz and the heir to the hero of the Uzbek epic Avaz provide a lot of material for our work.

As $\mathrm{H}$. Koroglu noted, Tajik bakhshis reworked the main plot of the Turkmen and Uzbek epics in accordance with the aesthetic requirements of the Tajik people. [1]

As I.S. Braginsky noted, Tajik bakhshis sang their individual ways of expression in every image, every event, every detail, especially the rhyme of written literature typical of the Shahnameh. The image of the voice is also artistically expressed in accordance with the tradition of the series "Heroes of Seystan". [3. 37] This uniqueness is one of the most characteristic features of the Tajik epic, in particular, the artistic interpretation of the image of Avaz. Researchers attribute this situation to the growing influence of written literature on folklore. [1. 178-179] With this in mind, in his article "Gorogly" Tajik folk epic "I.S. Braginsky assesses the poetic form of the Tajik epic, the composition of the epic as an example of" the stage of transition from Uzbek to Tajik." [3.10]

In the Tajik epic, Soqi is portrayed as an everchanging, even treacherous figure. He joins Ahmad and Yusuf and is degraded to the point of assassinating Avaz's son Nurali. This same approach is evident in the interpretation of other images as well. But the image of Avaz is embodied as a truly positive, beloved hero, loved by the people. Courage, bravery, honesty, justice, poverty, zeal for the defense of the country are the qualities of Avaz. [3. 130]

In the Tajik version, Avaz is interpreted in all epics as "Chambul's hero", ie defender, brave, fearless alp, "protector of the poor", supporter of the weak, "prince" who restores justice. In the epic, Avaz repeatedly defends the poor, the victims of injustice and oppression. In particular, he defeats the evil and tyrannical Farang sultan and distributes his treasure to the poor. Or Rayhan will save Bektashkul, who was imprisoned by an Arab, and bring justice to this country. Turabek freed Umarkhan, who had become a hero, and many other captives. [3. 124] 
He is uncompromising to Chambul's enemies, and in this way even he is embodied as a hero ready to die.. [3.129]

Chambuli-maston is an epic utopian space created by the people themselves. The people created it out of their own dream of what a just and prosperous kingdom should be like. In other words, it is a utopian-fantastic kingdom, just like Farobi's City of the Sun. It was built by the sultan of Gorogly. The events after the second epic of the epic coincide with the darkening of Gorogly. It is noteworthy that Gorogly is a hero of the Turkic peoples in every way. It is very difficult to reflect the dreams and epics of the Tajik people in this image. Because at the time of the formation of the Tajik epic, the image of Gorogly was formed. For this reason, Tajik poets pay close attention to the image of Avaz, interpreting him as an epic ideal hero. He not only invades Chambul, but also destroys enemies who intend to invade and zeal, becoming Chambul's defender. [3. 129]

\section{RESULTS AND DISCUSSION}

It is well known that epic is a genre that idealizes the heroes that the people themselves dream of. [4. 303] As V. Jirmunsky and $\mathrm{H}$. Zarifov noted, this kind of "idealization reflects the collective worldview" [4. 303], that is, the general perception of the people about heroism. In the epic, he is portrayed as a hero in the ideal of the people, whose qualities, attributes, characteristics, character are praised at the level of the ideal hero. This is evident in all the images associated with the image of the voice, in the artistic interpretation. It is through the folk baxshi that he expresses his dreams in his alpine. $V$. As Jirmunsky and $\mathrm{H}$. Zarifor noted, epic heroes are distinguished by their typicality, in other words, the epic hero embodies an entire nation. That is why in epic heroes there is no clear division between individual and collective, it is an image with both individual and collective characteristics. The epic protagonist differs from the heroes of written literature in that he embodies both the Individual and the collective heroism.

Written literature emphasizes the individual characteristics of the protagonist as an example of individual creativity. The hero of the epic, which is a collective creation, embodies the collective, that is, the collective image of the people about the hero. [4. 303]That is why the dreams and ideological goals of the people manifest themselves through the epic hero. The characteristics of an epic hero, his qualities, his qualities are the characteristics and traits of the people who created this epic. In this respect, the epic hero carries the basic ideas of the nation.

If we look at the issue from this point of view, the features and characteristics of the image of Avaz reflect the qualities and characteristics of the Uzbek and Tajik peoples. Both peoples assimilate their character, typical features, into the image of Avaz. For this reason, the epic space is described as "Turkmen people", "Yovmit", but in fact it is Uzbek for Uzbek, Tajik for Tajik. [5]

The epic alp is depicted in both folk epics with imaginative and expressive closeness. Accordingly, it can be said that the epic hero is the artistic embodiment of this worldview. The people concentrate on their ideal hero their vision of society, justice, heroism, courage, beauty. For this reason, in both versions, Avaz is portrayed as a handsome young man to the point of "embarrassing the moon." In fact, the beauty of Avaz is not only connected with the genesis of "kosagullik" in its historical genesis, but also with the people's beautiful image of the ideal hero, 
courage, honesty, justice, heroism in a beautiful image. This is most evident in the descriptions given to the external beauty of the image of the Voice. [6]

The people want their ideal to be beautiful in every way, including appearance. However, it should be noted that V. Jirmunsky and H. Zarif emphasized that when people idolize their hero, they use not only the external beauty, but also the inner image of the hero, that is, his heroic life. Therefore, "the appearance of the protagonist in the epic is at the same time an expression of the idealization of his spiritual qualities". [4. 308]

In the Tajik epic, the image of the voice is imbued with many lines of the hero Rustam in "Shohnoma". This is especially evident from his battle scenes. [3.140]

In the Uzbek epic, Avaz is also described as "Rustam Kelbatli".

The lines of the Avaz image in the Tajik epic are almost identical to the lines of the Avaz image in the Turkish epic. This is mostly evident in his appearance images. In both versions, Avaz is a "full moon", "golden hair", a handsome young man who captivates anyone with his beauty. [3. 58]

In the Uzbek version, Avaz is expressed in a unique way. [7.6]

It should not be overlooked that in both epics such similar descriptions of the image of the Voice are implied, both externally and spiritually. After all, in the genesis of the image of Avaz, the fact that he was the "flower of feasts" is preserved in the lines of the image. Thus, in both epics, Avaz is interpreted as a hero with both outward and spiritually beautiful qualities. To this end, the bakhshis of both nations make extensive use of the treasury of artistic expression in their epic traditions. The treasure trove of artistic expression is a poetic combination that has been passed down from generation to generation, polished, and contains many colors, meanings, and symbolic representations.

\section{CONCLUSION}

In short, in both versions, outwardly beautiful youth, the beauty of Avaz and "Yusuf Talatli" come to the fore in Roman adventures. It should be noted that little attention is paid to the adventures of Avaz, typical of the romantic epic, in the Tajik epic. Nonetheless, Avaz's journeys to bring the Zarnigor, the Black Eyed Peas, are entirely romantic adventures. In the rest of the epics, Avaz is full of adventures typical of a heroic epic, which, as I.S. Barginsky points out, is adapted to the "heroes of Seystan". Preserving the unity of the Avaz image in the plot and space, the Tajik bakhshi subordinated the image to their national aesthetic traditions, turned him into a Tajik hero, and absorbed the character of the Tajik people. However, there is a parallel with the Uzbek Avazi, from the artistic interpretation of the image to the ways of expression, the course of events, adventures and conflicts, battle scenes and family relationships. This indicates that the two peoples lived in one place, one culture and one kingdom, one civilization, on the basis of the same aesthetic laws.

\section{REFERENCES}

1. Korogly Kh.G. Interconnections of the epos of the peoples of Central Asia, Iran and Azerbaijan. Moscow: "Nauka", 1983.

2. Gegel G.V. Sochienin. Volume 14, Book3, Moscow, 1958. - p. 231. 
3. Gorogly. Tajik epic. Moscow: Main editorial board of Oriental literature, 1987. - pp. 7-8.

4. Jirmunskiy V.M., Zarifov Kh.T. Uzbek folk heroic epic. Moscow: OGIZ. Publish Political, 1947. - p. 303.

5. Beaver and Star. Doston. The narrator is the son of Ergash Jumanbulbul. Tashkent: Literature and Art, 1968.

6. Avazkhon. Doston. Narrator: Rahmatullah Yusuf oglu. Prepared by Tora Mirzaev. Tashkent: Yozuvchi, 1997. - p. 4.

7. Gorogly // Turkmen heroic epic. Main editorial office of oriental literature. Moscow, 1983. - p. 30.

8. Birth of Gorogly. Narrator: Muhammad Jamrad oglu is a polkan. Prepared by M.Murodov. Tashkent: Fiction, 1967. - p. 62.

9. Korogly Kh.G. The relationship of the epos of the peoples of Central Asia, Iran and Azerbaijan. Moscow: Nauka, 1975. - p. 336.

10. Mirzaev T. An epic repertoire of folk singers. Tashkent: Fan, 1979. - p. 133.

11. Mirzaev T. Epos and storyteller. Tashkent: Fan, 2008 . - p. 410. 